\title{
Elementos do pensamento econômico clássico e da geoeconomia nos processos migratórios do Brasil
}

Elements of classical economic thinking and geoeconomy in the migratory processes of Brazil

\author{
Roberto Georg Uebel \\ roberto.ueb@ufrgs.br \\ Universidade Federal do Rio Grande do Sul \\ (UFRGS)
}

\author{
Rita Ines Pauli \\ rita.pauli@gmail.com \\ Universidade Federal de Santa Maria \\ (UFSM)
}

Resumo: O artigo tem como objetivo resgatar os elementos teóricos da formação econômica do Brasil buscando contextualizar os processos imigratórios. Para tanto, buscou-se na literatura clássica da história econômica do Brasil os aportes teóricos e bibliográficos, bem como a abordagem de autores contemporâneos acerca do papel das migrações na formação econômica, dos capitais e capitalismo brasileiros entre o final do século XIX e primeira metade do século XX. Inferiu-se que a história econômica brasileira contribuiu relevantemente à consecução dos fluxos migratórios de europeus e asiáticos para o desenvolvimento econômico brasileiro. As contribuições da História Econômica do Brasil e da Geoeconomia são essenciais à interpretação das migrações, seus fluxos, repercussões e impactos na Economia como um todo. Celso Furtado, Caio Prado Junior, João Manuel Cardoso de Mello e outros se fazem, portanto, vivos e necessários também aos estudos das migrações econômicas.

Palavras-chave: Imigração; Brasil; História Econômica; Geoeconomia

Abstract: The article aims to recover the theoretical elements of the economic formation of Brazil in order to contextualize the immigration processes. In order to do so, we sought the theoretical and bibliographical contributions in the classic literature of Brazilian economic history, as well as the approach of contemporary authors on the role of migrations in the Brazilian economic and capital and capitalism formation between the late nineteenth and first half of the twentieth century. It was inferred that Brazilian economic history contributed significantly to the achievement of migratory flows of Europeans and Asians towards the Brazilian economic development. The contributions of the Brazilian Economic History and Geoeconomics are essential to the interpretation of migrations, their flows, repercussions and impacts on the Economy as a whole. Celso Furtado, Caio Prado Junior, Joao Manuel Cardoso de Mello and others are therefore also living and necessary for the study of economic migrations.

Keywords: Immigration; Brazil; Economic History; Geoeconomics

\section{INTRODUÇÃO}

Como embasamento teórico para as pesquisas histórico-econômicas de imigração no Brasil, se faz importante recorrer aos autores clássicos no desenvolvimento econômico 
brasileiro e latino-americano, o qual foi distinto daquele observado em outros países periféricos do Caribe, África e Ásia, conforme preconiza Mello:

O desenvolvimento latino-americano não é um desenvolvimento qualquer, mas um desenvolvimento capitalista; o desenvolvimento capitalista na América Latina é específico, porque realizado numa "situação periférica nacional". (MELLO, 1984, p. 25).

Assim, todo processo imigratório europeu e asiático com destino ao Brasil entre os séculos XIX e XX, teve seu início e apogeu nessa situação periférica nacional defendida por Mello (1984). Esse fato caracterizou toda uma conjuntura diferente no estabelecimento, incorporação e exposição da mão de obra imigrante, quando comparados os processos ocorridos em países vizinhos e no Brasil, embora ambos os processos estivessem inseridos em todo o contexto de desenvolvimento capitalista tardio latino-americano.

Deste modo, o presente texto tem como objetivo resgatar estes elementos de autores clássicos e inclui autores contemporâneos do pensamento e histórica econômica brasileira, além de autores contemporâneos oriundos da geoeconomia, a fim de explicar quais os seus impactos e repercussões nas imigrações históricas com destino ao Brasil.

Assim, dividiu-se o texto em duas principais seções, subdivididas em subseções, de acordo com os aportes da História Econômica e da Geoeconomia, agora como grandes áreas da Ciência Econômica. Na primeira seção analisamos e interpretamos os clássicos, Celso Furtado, Caio Prado Junior e João Manuel Cardoso de Mello, e na segunda seção partimos à compreensão do pensamento geoeconômico de autores mais contemporâneos, como José de Souza Martins e Francisco Vignoli.

\section{APORTES HISTÓRICO-ECONÔMICOS DA IMIGRAÇÃO}

Esta seção resgata contribuições teóricas de autores clássicos para a compreensão de elementos analíticos que norteiam a gênese dos processos imigratórios no Brasil.

\subsection{A imigração em Celso Furtado e a problemática da formação de um mercado de trabalho}

Celso Furtado (2001), em seu clássico trabalho Formação Econômica do Brasil, justifica a imigração para o território brasileiro como uma solução alternativa ao problema de mão de obra que atingia a produção brasileira, inspirada no exemplo dos Estados Unidos da América, tendo como aparato de intervenção governamental a instalação de colônias de 
imigrantes europeus e como questão fundamental aumentar a oferta de força de trabalho disponível para a grande lavoura brasileira.

No entanto, Furtado (2001) exemplifica que a emigração europeia aos Estados Unidos não tinha relações de reciprocidade com a oferta de mão de obra para as grandes plantações, sendo fenômenos autônomos que não poderiam ser justificativas para a ocorrência de igual processo no Brasil.

Percebe-se então que as colônias de europeus subvencionadas pelo governo imperial brasileiro careciam totalmente de fundamento econômico, sendo guiadas apenas pela crença na superioridade ingênita do trabalhador europeu, particularmente daqueles de origem distinta à dos europeus que haviam colonizado o Brasil, ou seja, espanhóis, neerlandeses e portugueses.

Cria-se assim uma barreira natural à imigração espanhola no início da expansão imigratória de trabalhadores europeus, visto que, conforme afirma Furtado (2001), os colonizadores iniciais eram evitados, por serem, nas atividades laborais e de cultivo da terra, inferiores aos alemães, italianos, poloneses e demais grupos que para cá emigraram. Assim, a imigração espanhola tardou-se, vindo a se acentuar apenas aos fins do século XIX, consoante se observará ao longo deste trabalho.

Segundo o autor, para que as colônias chegassem a constituir um êxito como política imigratória que transformaria os imigrantes em trabalhadores da grande lavoura brasileira, teria sido necessário que elas se dedicassem de imediato a atividades produtivas rentáveis.

Reconhecia-se assim que a política de imigração e colonização do governo imperial em nada contribuía para solucionar o problema de mão de obra da grande lavoura, ao mesmo tempo em que barrava a entrada de grupos migratórios, como os espanhóis. Além disso, a subvenção aos demais grupos combalia os cofres imperiais, levando a classe dirigente da economia cafeeira a preocupar-se diretamente com esse problema, que na época parecia, à primeira vista, insolúvel.

Resolvida essa questão, através da mudança de atitude política do governo brasileiro, com o fazendeiro cobrindo a parte principal do financiamento (o preço da passagem da família imigrante), criava-se o segundo problema apresentado por Furtado: a servidão sem tempo fixado e de caráter quase escravista, a qual levaria, com efeito, o custo real da imigração a recair sobre o imigrante, que era a parte financeiramente mais fraca do contrato.

A solução adotada e referida por Furtado (2001) surgiria em 1870, quando o governo imperial passou a encarregar-se dos gastos de transporte dos imigrantes que deveriam servir à lavoura cafeeira, e: 
[...] ao fazendeiro [por sua vez] cabia cobrir os gastos do imigrante durante o seu primeiro ano de atividade, isto é, na etapa de maturação de seu trabalho. Também devia colocar à sua disposição terras em que pudesse cultivar os gêneros de primeira necessidade para manutenção da família. Dessa forma o imigrante tinha seus gastos de transporte e instalação pagos e sabia a que se ater com respeito à sua renda futura. (FURTADO, 2001, p. 127).

Assim, esse conjunto de políticas de incentivo à vinda dos imigrantes europeus tornou possível a promoção, pela primeira vez no continente americano, de uma volumosa corrente imigratória de origem europeia destinada a trabalhar em grandes plantações agrícolas.

Posteriormente, estas grandes plantations seriam exclusivamente de cunho cafeeiro, tornando possível, assim, a expansão da produção cafeeira no estado de São Paulo, segundo Furtado (2001), e, no caso do estado do Rio Grande do Sul, o desenvolvimento e a prosperidade econômica do Vale dos Sinos, Vale do Taquari, Região das Hortênsias e Serra Gaúcha, locais onde os imigrantes europeus - nessa fase alemães e italianos - inicialmente se instalaram.

\subsection{Caio Prado Júnior e as determinações econômicas, políticas e militares do processo imigratório brasileiro}

Enquanto Furtado (2001) faz uma breve referência sobre a importância e o desenrolar inicial da imigração no território brasileiro, Caio Prado Júnior (1994) dedica um capítulo de sua obra História Econômica do Brasil e praticamente toda sua obra Formação do Brasil Contemporâneo ao tema da imigração e colonização como determinantes do desenvolvimento e formação econômica do Brasil. Além de inferir os objetivos econômicos da imigração, já apontados por Furtado (2001), Prado Júnior (1994) resgata também os seus objetivos políticos e militares.

A problemática da rivalidade entre espanhóis e portugueses novamente barrou a entrada de imigrantes espanhóis em território brasileiro, especialmente no Rio Grande do Sul, segundo Prado Júnior (1994), pelo fato de que:

Empregou-se [o imigrante], sobretudo para povoar e ocupar regiões de valor estratégico que a imigração espontânea deixava ao abandono; foi o caso de alguns setores fronteiriços da colônia que a metrópole desejava ver ocupados e assim defendidos contra a concorrência espanhola. (PRADO JÚNIOR, 1994, p. 183). 
Isso foi o que ocorrera em Santa Catarina e no Rio Grande do Sul: empregaram-se em sua maioria colonos naturais dos Açores, facilitando-lhes o transporte e estabelecimento. Pode-se observar que a Espanha agira de forma igual e com o mesmo objetivo no território uruguaio, utilizando colonos provindos das Ilhas Canárias, sendo essa a origem do povoamento de Montevidéu.

Dessa forma, foi somente depois da transferência da corte portuguesa para o Brasil, em 1808, que a imigração e a colonização se ampliam, adquirindo finalidade própria e exclusivamente demográfica. Após a partida do Rei Dom João VI para Portugal, segundo Prado Júnior (1994), os governos subsequentes (até o início do século XX) continuariam a tarefa empreendida por ele; contudo, as agitações políticas do momento e as graves dificuldades financeiras enfrentadas pelos governos não ofereciam oportunidades para ações governamentais imigrantistas mais eficientes.

Aliás, ressalta-se que o problema da imigração europeia oferecia grandes dificuldades para o Brasil até metade do século XX. Contra ela atuavam diversos fatores expostos por Prado Júnior (1994): o clima tropical desfavorável a colonos europeus; a organização social e econômica que o país oferecia; o regime político vigente, no qual, embora sob a égide mascarada de instituições parlamentares, a liberdade civil era inexistente ou praticamente cerceada em todas suas esferas para a massa da população. Havia ainda, até o fim da República Velha, restrições de ordem religiosa que punham sério embaraço à imigração dos países protestantes da Europa, justamente aqueles que forneciam então os maiores contingentes emigratórios.

Prado Júnior (1994) aponta para a melhor adaptabilidade e receptividade dos territórios sul-rio-grandenses aos imigrantes europeus, tendo como fatores determinantes para isso o interesse e o estímulo dos governos locais em aumentar a produtividade da terra com mão de obra europeia, a riqueza e a prosperidade da Região Sul, e o próprio clima favorável, que Prado Júnior (1994) definiu como um "polo único de atração, no Brasil, das correntes imigratórias".

Continuando, o autor estabelece que foi tentado para o Rio Grande do Sul um sistema de colonização original, com particularidades que o distinguiam nitidamente do sistema de imigração brasileiro. Como não se tratava de regiões aptas para a produção de gêneros tropicais de grande valor comercial, como o açúcar e o café, foi preciso, para conseguir povoadores (providência necessária por se tratar de um território contestado pela Espanha), recorrer às camadas pobres ou médias da população portuguesa, alemã e italiana. 
Conforme Furtado (2001) também citara em sua obra, o custo do transporte seria financiado pelo governo brasileiro, sendo a instalação dos colonos cercada de toda sorte de providências para facilitar e garantir a subsistência dos povoadores: as terras a serem ocupadas eram pequenas parcelas (pois não eram destinadas às grandes lavouras tropicais) previamente demarcadas.

Há que se salientar, porém, que o processo específico de imigração no Rio Grande do Sul muito difere do ocorrido no Brasil e países vizinhos em geral, dadas as suas condições territoriais e climáticas, conforme aponta Prado Júnior (1994) em seu capítulo acerca da incorporação do Rio Grande do Sul e do estabelecimento da pecuária. Isto acaba por confirmar, portanto, por meio do aporte de dois grandes autores clássicos na literatura econômica do Brasil, o caráter diferenciado do processo imigratório naquele estado.

\subsection{João Manuel Cardoso de Mello e a imigração como forma de colonização para o capital}

João Manuel Cardoso de Mello (1984) também faz uma breve explanação sobre a questão imigratória no desenvolvimento econômico brasileiro, ponderando que, além de contar com o crescimento vegetativo da população urbana, a retomada da imigração foi decisiva, a qual foi possível graças ao extraordinário crescimento da oferta no mercado internacional do trabalho.

Mello (1984), fazendo uma analogia ao processo de utilização do trabalho escravo em vez do trabalho imigrante, apontava o pensamento pré-capitalista da época, ao dizer que somente "haveria produção colonial se houvesse trabalho compulsório, servil ou escravo" (MELLO, 1984, p. 39).

Nessas condições, obter produção mercantil em larga escala significava assalariar a força de trabalho, o que exigiria que a taxa de salários oferecida fosse suficientemente elevada para compensar, aos olhos dos colonos, a alternativa da autossubsistência. Assim, na visão do autor, o trabalho compulsório era a priori mais rentável que o emprego de trabalho assalariado imigrante, o que justifica a relutância dos pequenos e médios cafeicultores em aceitar esse tipo de mão de obra, conforme apontaram Furtado (2001) e Prado Júnior (1994).

A fim de evitar os problemas advindos da abolição da escravatura, os cafeicultores, segundo Mello (1984), optaram logo de início pela imigração de famílias europeias como mão de obra. O autor acrescenta que: "Como se tratasse de 'colonizar para o capital' e não colonizar para povoar, para ocupar vazios territoriais, a introdução de núcleos de colonização de nada valia, era puro desperdício". (MELLO, 1984, p. 84). 
Aqui se observa uma grande contradição entre Mello (1984) e os autores Furtado (2001) e Prado Júnior (1994): enquanto os dois últimos defendiam que a imigração poderia sim ser de povoamento, como no caso do Rio Grande do Sul, Mello (1984) entende que a imigração seria apenas para colonizar o capital, isto é, para manter as estruturas coloniais de reprodução daquele capitalismo euro-brasileiro. Contudo, ele concorda com ambos nos quesitos de participação do Estado no subsídio à imigração e a lucratividade dessa mão de obra específica, conforme segue:

[...] a União resolve empregar um terço dos recursos antes destinados in totum à formação de um fundo de emancipação, para subsidiar a imigração. Deixava-se claro, de outra parte, que a imigração se financiava era para o café, pagando-se a passagem apenas e tão-somente para colonos que se dirigissem a estabelecimento agrícola. (MELLO, 1984, p. 87).

Percebe-se, entretanto, divergências na análise dos autores a respeito da necessidade da mão de obra imigrante e das políticas que a trouxeram para o Brasil, colocando Celso Furtado e Caio Prado Júnior em uma esfera e João Manuel Cardoso de Mello em outra.

\section{DO PENSAMENTO CLÁSSICO AO CONTEMPORÂNEO: A GEOGRAFiA ECONÔMICA E A DINÂMICA REGIONAL NO PROCESSO IMIGRATÓRIO}

Diversos outros autores brasileiros escreveram sobre o processo imigratório ocorrido em território brasileiro desde o período colonial até a imigração contemporânea. Nesse sentido, esta seção analisa dois autores que contribuíram significativamente para a construção do pensamento imigrantista na teoria econômica. José de Souza Martins (1973) e sua célebre obra A Imigração e a Crise do Brasil Agrário são considerados marcos de referência na teorização da imigração na literatura econômica clássica e sociológica, lançando as bases para seu estudo e compreensão. Na contemporaneidade, Francisco Vignoli (2003) contribui com grande relevância através do capítulo "A Imigração e a Formação do Mercado de Trabalho", pertencente à obra Formação Econômica do Brasil, de José Márcio Rego e Rosa Maria Marques (2003), sendo a mais recente abordagem sobre imigração na literatura econômicohistórica brasileira.

\subsection{A imigração e a formação territorial, identidade nacional e categoria racial em José de Souza Martins}

José de Souza Martins (1973) discorre sobre a convergência entre as condições de emigração e de imigração, em que o aldeão, num caso, e o imigrante, no outro, emergiam 
como trabalhador livre, o que em ambas as situações significava a subjugação às objetivações da sociedade de classes. O verdadeiro sentido da migração não transparecia na passagem de uma sociedade nacional a outra, mas sim na coisificação da pessoa como resultado do seu envolvimento e redefinição pelas transformações históricas que deslocavam a matriz da existência da comunidade para a classe.

No dilema da emigração, Martins trata de incorporar a influência do novo capitalismo que emergia no continente europeu como determinante de uma "expulsão pacífica" dos seus nacionais ao continente americano. Para o autor, diversas seriam as causas que explicam o fenômeno de emigração maciça, mas "[...] essas causas não operariam ou nem sequer teriam aparecido se a estrutura social fosse outra. É sintomático que tenham surgido simultaneamente com a expansão do capitalismo [...]" (MARTINS, 1973, p. 74-75).

Com essa citação o autor já se insere em um dos principais argumentos deste trabalho: a replicação das atividades de exploração ambiental, territorial e econômica no país que recebe imigrantes europeus. Curioso é o fato de Martins (1973) já arguir esse fundamento quatro décadas atrás, quando o processo migratório era muito recente e sua ingerência sobre os estudos acadêmicos era praticamente nula no Brasil.

O autor, em sua contribuição para este estudo da imigração no Brasil agrário, ainda exterioriza outro ponto polêmico e interessante: a decisão de emigrar foi, em sua grande maioria, antecedida por uma reiterada experiência migratória, sendo que, através dessa mesma migração temporária interna, o trabalhador absorvia diretamente as condições econômicas adversas. Novamente, Martins (1973) coloca-se diante do argumento deste trabalho e leva-nos a pensar que os imigrantes, por meio de sua sociologia de acolhimento e inserção socioeconômica, replicaram, para onde emigraram e estabeleceram suas atividades sociais e econômicas, aquilo que provinha de suas migrações anteriores, o que surpreende todo e qualquer estudo sobre imigração recente, pois estes afirmam que, após muitas experiências anteriores, a comunidade imigrante evita replicar o que realizava em sua sociedade de origem.

Essa circunstância aponta que, via de regra, o emigrante se submetera a um processo que não ficava sob seu domínio. Assim, a partir do momento em que se punha nas mãos do agenciador de imigrantes, conforme se citou em Furtado (2001) e Prado Junior (1994) anteriormente, fosse ele representante do governo estrangeiro ou intermediário local, o emigrante cedia inteiramente a uma ordem de decisões cujas matrizes lhe eram estranhas e estavam no mercado internacional da força de trabalho, levando consigo apenas seu feeling econômico e relações sociais familiares, que reproduziria além-mar. 
Todavia, para Martins (1973), em um ponto suspendiam-se as ambivalências: na convergência entre as condições de emigração e as de imigração. Nelas, o camponês, num caso, e o imigrante, no outro, emergiam como trabalhador livre (potencial ou realmente). Logo, os imigrantes agora estão enquadrados em uma classe trabalhadora distinta, o que facilita a análise do seu perfil laboral e propriamente sua inserção social e organização jurídica.

As verossímeis oportunidades que a sociedade brasileira da época oferecia ao imigrante estabelecido no local já estavam determinadas por razões que vinham desde sua partida no país de origem, como observado anteriormente. A indústria do empresário absenteísta, ou seja, vinculada ao grande capital, constituía a única possibilidade para uma definição típica e precisa do trabalhador como operário; por ora, o imigrante jamais (ou apenas em casos pontuais) teria oportunidade de instalar-se por primeira vez como empresário ou comerciante, sempre assumindo um serviço braçal e operário.

A situação do imigrante apresentou-se então duplamente polarizada, consoante à situação em que este chegara ao Brasil: em um plano marcado pela mediação da grande lavoura e noutro pela presumível autonomia do pequeno proprietário, ainda que rara e pontualmente localizada. Tal duplicidade exprimiu-se não só no pauperismo, na concentração da propriedade da terra e na localização da indústria, mas também na falta de reciprocidade na interação entre o imigrante e a classe dominante da sociedade inclusiva, definida pelo difícil entendimento das intenções do imigrante quando manifestadas em desacordo com os pressupostos da política de colonização e imigração.

Vale destacar ainda a contribuição de Martins no que tange à situação da posse das terras por parte dos imigrantes, ainda que estas fossem pequenas e sua legitimidade fosse questionada. Pelo que consta, o imigrante encontrava-se em uma situação de pura obediência e de não contestabilidade, não somente ante o seu empregador e seu agenciador, mas também ante o próprio Estado brasileiro e seus poderes, o que ilustra o trecho a seguir:

A precária diferenciação da economia e da sociedade brasileiras de então não lhe oferecia [ao imigrante] senão, fora da dependência exclusiva da pequena propriedade, uma faixa de mobilidade que ia apenas da situação marginal dos antigos agregados, foreiros e posseiros até as ocupações no cerne da agricultura de exportação e suas variantes mais sofisticadas no artesanato e comércio urbanos. (MARTINS, 1973, p. 169).

Constata-se, assim, que o imigrante não tinha opções de trabalho e atividade sociais diversas a optar, senão as que o próprio Martins (1973) evidenciara anteriormente e que se 
constituía em um escopo estreito de possibilidades de inserção produtiva. As alternativas que o imigrante tinha pela frente ou diziam respeito à inserção direta na cafeicultura já saturada de braços, ou nas ocupações dela derivadas, mas de qualquer modo o seu horizonte de vida permanecia marcado pela economia de exportação. Comprova-se essa baixa mobilidade sociolaboral imigrante com a Tabela 1.

Tabela 1 - Movimento da população imigrante no Estado de São Paulo (1877-1879)

\begin{tabular}{|c|c|c|c|c|c|}
\hline Período & Entradas & Saídas & Nascimentos & Óbitos & $\begin{array}{c}\text { População } \\
\text { presente }\end{array}$ \\
\hline $28 / 07 / 1877$ & - & - & - & - & 112 \\
\hline $28 / 071877-20 / 10 / 1877$ & 156 & 21 & 4 & 18 & 121 \\
\hline $01 / 08 / 1877-31 / 12 / 1877$ & - & - & - & - & 118 \\
\hline $28 / 07 / 1877-31 / 12 / 1879$ & - & - & 16 & 31 & 169 \\
\hline
\end{tabular}

Fonte: Martins (1973, p. 171), adaptada.

Desse modo, verifica-se, em consonância com a tabela 1, o que o próprio autor discorrera em sua obra: a baixa mobilidade dos imigrantes dentro do Brasil, em virtude das suas escassas possibilidades de mudanças e até mesmo de ascensão social. O núcleo colonial e imigrante transparece, assim, com a sua feição derradeira e básica: aglomerado de membros do grande operariado imigrante em inatividade ou subemprego constituído primordialmente em função da grande lavoura, mas secundariamente referido também aos outros setores gerados por ela.

A condição do colono como objeto de processos inclusivos alheios ao seu domínio, manifestados e oriundos na decisão de emigrar e a partir dela vivenciados, não podia completar-se senão nos estereótipos que categorizavam os seus contatos na sociedade receptora. Com essa diretriz, entre os defensores da imigração havia grande preconceito contra caboclos, chineses, turcos e asiáticos em geral, os quais, segundo o pensamento da época, não traziam a possibilidade de instituir no Brasil uma agricultura moderna.

Em consequência desse pensamento vigente inclusive na diplomacia brasileira, diferentes nacionalidades passaram a ser associadas positiva ou negativamente. Diversos pronunciamentos de agentes do Estado brasileiro e da grande lavoura mostravam quais as características ressaltadas em cada nacionalidade:

Os colonos italianos [e espanhóis] satisfazem melhor aos proprietários. Contentam-se com pouco, são muito econômicos e mais fáceis de dirigir que os colonos alemães, que parecem ter aversão pela cultura do café. (MARTINS, 1973, p. 177). 
Identificar-se com a nacionalidade, para Martins (1973), significava, pois, implicitamente ajustar-se às expectativas constituidoras da sociedade apoiada na economia colonial. Devido a essa adequação, imigrantes oriundos de uma Itália recém unificada, habituados a conhecerem-se antes como lombardos, vênetos, romanos, etc., passaram a ser denominados exclusivamente italianos, o que acontecera mais cedo com galegos, asturianos, etc. que foram centrados unicamente na denominação de espanhóis ou, erroneamente, castelhanos.

Na conclusão desta breve análise de Martins (1973), que faz uma compilação da situação sociológica e econômica do imigrante, observa-se a passagem do colono imigrante a membro do que o autor resgata apropriadamente de Marx, a membro do exército de reserva, daí a inversão do sentido da categorização racial para ele - de coroamento da ideologia do trabalho ela se mostrou como o que efetivamente era: apenas a estereotipação que individualizava e mobilizava as pessoas no mercado de trabalho.

O desabrochar entre os colonos de uma utopia comunitária confundindo comunidade e identidade nacional de origem, apesar da ambiguidade que a marcou devido à persistência da categorização racial, ainda que nuançada, significou a redefinição desta em termos negadores do seu sentido original, ou seja, a ideologia que separava metamorfoseava-se na utopia que unia; o imigrante novamente passava a ser uma categoria específica da economia brasileira, agora sob a ótica detalhada de José de Souza Martins (1973).

\subsection{A contribuição analítica de Francisco Vignoli: o papel da imigração na formação do mercado de trabalho}

Na obra Formação Econômica do Brasil, um compêndio histórico-econômico organizado Rego e Marques (2003), tem-se a condensação, sem perdas de conteúdo, de toda abordagem histórico-econômica desde o Brasil colonial até as consequências do processo de substituição de importações que aqui ocorreu em meados do Século XX. Nessa obra vislumbra-se a importante contribuição histórico-econômica, no que tange à imigração e à formação do mercado de trabalho, empreendida pelo pesquisador Francisco Vignoli (2003).

Vignoli (2003) subdivide o processo de imigração no Brasil em três partes: a) a expansão cafeeira e a lei de terras; b) as experiências iniciais de imigração e, c) a imigração subvencionada. Essas três fases constituíram todo o processo imigratório ao Brasil, sendo que na contemporaneidade adentramos em uma quarta fase, que poderia ser assim chamada de “imigração contemporânea ao Brasil”, com suas especificidades que serão debatidas posteriormente. 
O aumento da produção cafeeira na segunda metade do século XIX, ocorrido em virtude da incorporação de novas áreas de cultivo, necessitava grande quantidade de mão de obra que permitisse a expansão dessa produção, e é aí, segundo Vignoli, que começa a problemática da imigração ao Brasil, visto que, à época, a forma tradicional de obtenção da força de trabalho (escravatura) encontrava-se estancada, tornando-se um obstáculo ao pleno desenvolvimento da cultura cafeeira e ao próprio crescimento econômico brasileiro desse período. Na corte e nos centros econômicos que já existiam no país, clamava-se por uma reorganização institucional e política, surgindo a necessidade da imigração já em 1850, conforme aponta Vignoli (2003):

Com efeito, essa reorganização institucional já se fazia sentir nas palavras de Dom Pedro II, em $1^{\circ}$ de janeiro de 1850 , quando, entre outros assuntos, realçava a urgência de suprir a agricultura de braços, de preferência por meio da imigração de colonos livres. (VIGNOLI, 2003, p. 113).

Esse fora o primeiro passo para a criação e posterior incorporação das políticas imigrantistas em território brasileiro. O fim inevitável da escravatura, condenada pela extinção do tráfico negreiro imposto pela Inglaterra com fins comerciais e políticos no Brasil, exigia a elaboração de uma política imigrantista. É bem verdade que uma política de imigração e colonização já vinha sendo posta em prática desde a época de Dom João VI, em virtude da necessidade de povoar o país e garantir a sobrevivência da corte que aqui se instalara em 1808. Todavia, esse tipo de política imigrantista não supria as necessidades prementes do setor de produção cafeeira, evidenciando-se assim o fato de que tal política teria de perder seu vínculo exclusivo com os núcleos de povoamento.

É válido contrapor esse argumento com o exposto por Prado Júnior (1994), ou seja, que a imigração ocorrida no estado do Rio Grande do Sul fora diferenciada dessas políticas de promoção e sobrevivência da produção do setor cafeeiro no Sudeste brasileiro, pois nesse estado sempre houve a necessidade do povoamento ligada a questões sociais e territoriais, sendo a questão econômica e produtiva colocada em segundo lugar, retornando assim ao "processo específico de imigração" que ocorrera nesse estado sulino.

Uma das preocupações dos agricultores paulistas era de que a simples modificação da política imigrantista - privilegiando a imigração em detrimento da política de colonização que já era posta em prática - não significasse a transformação do imigrante em força de trabalho da grande lavoura. Temiam que, em uma região onde a aquisição de terras só fosse viável através da ocupação formal e acessível a todos, seria praticamente impossível conseguir mão 
de obra para o trabalho nas fazendas. Nessa situação, o imigrante seria potencialmente um futuro proprietário, não se constituindo em força de trabalho disponível; novamente, totalmente distinto do processo de imigração que ocorrera no Rio Grande do Sul, o que denota uma dualidade de políticas imigrantistas, no mesmo período de tempo e no mesmo país.

Assim, com a Lei n. 601, de 18 de setembro de 1850, incorporaram-se todas as sugestões que atendiam diretamente aos anseios da nova classe dirigente brasileira, isto é, os grandes cafeicultores. Aqui já se legislava a respeito da configuração dos colonos e imigrantes que viessem a residir em território brasileiro:

Art. 17. Os estrangeiros que comprarem terras, e nellas se estabelecerem, ou vierem á sua custa exercer qualquer industria no paiz, serão naturalisados querendo, depois de dous annos de residencia pela fórma por que o foram os da colonia de S, Leopoldo, e ficarão isentos do serviço militar, menos do da Guarda Nacional dentro do municipio.

Art. 18. O Governo fica autorizado a mandar vir annualmente á custa do Thesouro certo numero de colonos livres para serem empregados, pelo tempo que for marcado, em estabelecimentos agricolas, ou nos trabalhos dirigidos pela Administração publica, ou na formação de colonias nos logares em que estas mais convierem; tomando anticipadamente as medidas necessarias para que taes colonos achem emprego logo que desembarcarem." [Mantida a grafia original da época]. (BRASIL, 1850).

A grande contribuição dessa lei, que atualmente serve apenas como registro histórico do processo evolutivo da imigração no Brasil, é que esta cita a colônia de São Leopoldo, no estado do Rio Grande do Sul, onde inclusive o processo de naturalização dos imigrantes é distinto daquele ocorrido no restante do Brasil, sendo esta opcional. Nota-se novamente um dos argumentos basilares deste trabalho de que tanto o processo imigratório como a colonização do Rio Grande do Sul foram ímpares em seu sentido e meio em relação ao Brasil - sendo a Lei n. 601 um exemplo relevante -, além de terem sido determinantes da atual constituição territorial e econômica desse estado.

Por fim, Vignoli (2003), no primeiro subcapítulo do seu trabalho, em que aborda a primeira fase do processo imigratório no Brasil, termina expondo que a adoção dos preceitos da Lei n. 601 significava que a propriedade da terra só seria conquistada pelo imigrante através do seu trabalho, realizado previamente nas fazendas de café, apresentando assim a associação entre política de terras e política de mão de obra, o que demonstra o poder político dos grandes proprietários, especificamente dos grandes cafeicultores.

Ao adentrar na análise das experiências iniciais de imigração, Vignoli (2003) aborda dois subgrupos: o sistema de parceria e os núcleos oficiais de colonização, ambos 
subvencionados pelo capital cafeeiro privado, visto que, embora se afirmasse, genericamente, que os imigrantes deveriam vir ao país para trabalhar na grande lavoura, a finalidade era bastante restrita: trabalhar na lavoura do café, nossa principal riqueza à época.

O autor descreve ainda a importância da imigração alemã e italiana no Sul do Brasil, a qual foi o motor propulsor de todo processo de imigração no Brasil, ainda que Uebel (2011) aponte os processos anteriores de colonização francesa e neerlandesa no Nordeste brasileiro. De curta duração, esse processo imigrantista alemão entra em declínio já no início de 1850 , principalmente porque as correntes imigratórias alemãs não mais demonstram o mesmo interesse em vir para o Brasil. Embora fugaz, esse processo imigrantista, que caracteriza a política governamental de povoamento do país, dever ser analisado no contexto do então pensamento dominante, ou seja, que a colonização deveria ser realizada por homens livres e brancos, que aqui se tornariam pequenos proprietários.

Algumas outras experiências no sentido de trazer imigrantes para o país foram realizadas, e a mais importante delas, principalmente pelos problemas que originou, foi o sistema de parceria. Tal sistema foi adotado pela primeira vez em 1847 pelo então senador Vergueiro, na fazenda de Ibicaba, estado de São Paulo, onde foram estabelecidos 423 colonos alemães, sendo fundada então por esse senador a empresa Vergueiro \& Cia., que, com o apoio do governo imperial, passa a dedicar-se à introdução de imigrantes também para outros cafeicultores, conforme aponta Vignoli (2003).

No sistema de parceria, conforme Vignoli (2003), os colonos eram contratados no continente europeu, tendo a viagem paga, bem como o transporte até a fazenda, seu local de atividade laboral. Todas as despesas relativas ao transporte e à manutenção eram adiantamentos que deveriam ser quitados a partir do momento em que os colonos pudessem sustentar-se pelo próprio trabalho, ou seja, arcar com a própria subsistência:

Sobre os adiantamentos eram cobrados juros de $6 \%$ ao ano. A cada família era atribuída certa quantidade de pés de café para cultivar e colher. Elas poderiam plantar, entre as filas de café, alguns gêneros necessários ao próprio sustento. Em caso de venda desses gêneros, o fazendeiro teria direito à metade da receita obtida. Quando o café fosse vendido, o colono teria direito à metade do lucro líquido, deduzidas todas as despesas com o beneficiamento, transporte, impostos, etc. (VIGNOLI, 2003, p. 118).

Como os colonos começavam a trabalhar totalmente endividados, o que os impossibilitava de trabalhar em outra atividade que lhes pudesse render algum ganho extra, a relação entre fazendeiros e colonos começou a ficar cada vez mais conflituosa e menos 
lucrativa ao cafeicultor empreendedor da imigração de parceria, levando a um fracasso total do sistema. Entre os principais motivos apontados por Vignoli (2003), destacava-se o fato de que, tendo realizado adiantamentos que possibilitariam não só a vinda como também a manutenção do imigrante por certo período e que constituíam um efetivo desembolso de capital, os fazendeiros desenvolveram artifícios para manter o imigrante em suas fazendas.

O grande problema desse sistema, que durou exatamente dez anos, sendo extinto em 1857, foi que o arranjo de emprego de mão de obra estrangeira, baseado principalmente na parceria e depois evoluindo para o trabalho assalariado, estabeleceu condições pouco favoráveis às soluções dos problemas econômicos dos imigrantes.

Estando esse sistema caído no limbo das políticas privadas de subsídio à imigração, a segunda etapa inicial da imigração apontada por Vignoli (2003) foram os "Núcleos Oficiais de Colonização", que, assim como o Sistema de Parceria, tiveram vida curta. Conforme se afirmou anteriormente, a colonização do país obedecia, inicialmente, à orientação de trazer o imigrante para tornar-se um pequeno proprietário de terras, o que sofria total hostilidade por parte dos cafeicultores paulistas, os quais tinham a preocupação de que tal atitude não resolvesse o problema da falta de braços para a lavoura cafeeira. O principal argumento usado à época era "o de que de nada adiantaria aumentar a população do país por meio da imigração, se esta não fosse orientada para possibilitar o fornecimento de força de trabalho para a lavoura cafeeira." (VIGNOLI, 2003, p. 119).

Vignoli (2003) refere que se, no caso de São Paulo, os núcleos oficiais de colonização tiveram a função de atrair imigrantes a fim de aumentar a oferta de mão de obra para a economia em geral e, principalmente, fornecer braços à lavoura cafeeira, a colonização europeia no Sul do país, indiretamente, também se prestou a esses mesmos objetivos, principalmente ao último. Contudo, trata-se de um processo imigratório específico, dado que estava inserido em segundo plano no real objetivo de imigração ao Rio Grande do Sul.

Mesmo assim, essa política imigrantista ainda não satisfazia aos cafeicultores, pois muitas das colônias oficiais não estavam próximas às fazendas, não podendo aqueles a estas recorrer, na medida de suas necessidades, gerando despesas aos fazendeiros. A solução foi dada a partir do momento em que o Estado passou a financiar a imigração, encaminhando os colonos diretamente para os cafezais, o que, segundo Vignoli (2003), marca o surgimento da terceira fase da imigração no Brasil: a imigração subvencionada.

Logo, a partir do momento em que o Estado brasileiro passou a financiar a imigração, responsabilizando-se pelo recrutamento, transporte e distribuição dos trabalhadores, assegurou-se, na concepção de Vignoli (2003), a entrada contínua de imigrantes nas fazendas, 
garantindo-se a expansão da cafeicultura. Nessa orientação, a presença do Estado foi determinante, visto que, ao financiar a imigração, subsidiou a formação do capital do empreendimento cafeeiro, contribuindo, muito posteriormente, conforme aponta Mello (1984), para a decolagem da industrialização tardia do Brasil.

A importância desses subsídios concedidos pelo governo imperial em prol da política imigrantista pode ser percebida ao considerar-se que, no ano de 1888, o governo provincial paulista tomou emprestado, em Londres, 749 mil libras esterlinas, o que representava o dobro da sua receita anual e boa parte do orçamento de todo o império. Segundo aponta Vignoli (2003), no biênio 1887-1888, aproximadamente $70 \%$ do orçamento provincial fora comprometido com a política de subsídios à imigração, o que se reflete inclusive no orçamento imperial. Tais dados se comprovam na Tabela 2.

Tabela 2 - Subsídios à imigração no Brasil (1885-1900) em libras esterlinas (f)

\begin{tabular}{|c|c|c|c|c|}
\hline Ano & Governo imperial $(\mathrm{A})$ & Governo paulista $(\mathrm{B})$ & Total $(\mathrm{A}+\mathrm{B}=\mathrm{C})$ & $\mathrm{B} / \mathrm{C} \%$ \\
\hline 1885 & $£ 80.430,78$ & $£ 28.343,82$ & $£ 108.774,60$ & $26,1 \%$ \\
\hline 1886 & $£ 160.619,27$ & $£ 88.172,13$ & $£ 248.791,40$ & $35,4 \%$ \\
\hline 1887 & $£ 251.734,00$ & $£ 299.447,62$ & $£ 551.181,62$ & $54,3 \%$ \\
\hline 1888 & $£ 405.395,21$ & $£ 304.383,88$ & $£ 709.779,09$ & $42,9 \%$ \\
\hline 1889 & $£ 703.153,53$ & $£ 17.541,18$ & $£ 720.694,71$ & $2,4 \%$ \\
\hline 1890 & $£ 327.322,21$ & $£ 83.918,70$ & $£ 411.240,91$ & $20,4 \%$ \\
\hline 1891 & $£ 1.224 .275,18$ & $£ 37.382,66$ & $£ 1.261 .657,84$ & $3,0 \%$ \\
\hline 1892 & $£ 346.374,96$ & $£ 75.565,31$ & $£ 421.940,27$ & $17,9 \%$ \\
\hline 1893 & $£ 301.319,60$ & $£ 180.554,46$ & $£ 481.874,06$ & $37,5 \%$ \\
\hline 1894 & $£ 99.067,25$ & $£ 51.318,40$ & $£ 150.385,65$ & $34,1 \%$ \\
\hline 1895 & $£ 339.878,38$ & $£ 301.398,25$ & $£ 641.276,63$ & $47,0 \%$ \\
\hline 1896 & $£ 679.561,38$ & $£ 175.406,26$ & $£ 854.967,64$ & $20,5 \%$ \\
\hline 1897 & $£ 30.887,30$ & $£ 190.619,57$ & $£ 221.506,87$ & $86,1 \%$ \\
\hline 1898 & $£ 40.485,88$ & $£ 82.039,29$ & $£ 122.525,17$ & $67,0 \%$ \\
\hline 1899 & $£ 7.942,15$ & $£ 70.607,19$ & $£ 78.549,34$ & $89,9 \%$ \\
\hline 1900 & $£ 75.213,94$ & $£ 44.685,92$ & $£ 119.899,86$ & $37,3 \%$ \\
\hline
\end{tabular}

Fonte: Vignoli (2003), adaptada e corrigida.

A política imigrantista mostrava então sua eficiência ao recrutar e subsidiar cidadãos totalmente sem recursos, que eram atraídos pelas passagens gratuitas fornecidas pelo governo brasileiro e pela propaganda que acenava com a possibilidade de tornarem-se, aqui no Brasil, proprietários de terras, conforme debatido anteriormente. É curioso notar que esse processo se reverteu ao longo dos séculos XX e XXI, quando brasileiros são atraídos pela propaganda coeteris paribus similar de abastada e confortável vida na Espanha, por exemplo, conforme aborda Uebel (2012) em sua pesquisa acerca da imigração espanhola para o Brasil.

Ainda é importante destacar, a partir do que discute Vignoli (2003), que quando se analisa o processo imigratório em geral e, sobretudo, o processo com as características do ocorrido em território brasileiro no período em questão - fins do século XIX e início do 
século XX -, é necessário caracterizar os fatores de atração dos imigrantes, ou seja, aqueles responsáveis pela vinda dos imigrantes ao país, bem como, considerando os países de origem, os fatores responsáveis pela expulsão daqueles nacionais que imigravam.

É a partir da combinação desses fatores que se busca a explicação para o amplo processo imigratório que particulariza a economia mundial, a partir da segunda metade do século XIX, no qual se insere o caso brasileiro e suas duas formas de imigração, a do Rio Grande do Sul e a do restante do país.

Portanto, em decorrência da política imigrantista desenvolvida pelo Estado, foram criadas as condições necessárias para que a formação de fazendas e sua posterior venda se transformassem em uma atividade muito lucrativa tanto no Sudeste brasileiro como no processo específico do Rio Grande do Sul, onde possibilitou a formação de núcleos urbanos e regionais e a criação a posteriori das regiões econômicas diferenciadas, como por exemplo: Vale dos Sinos (alemães); Bagé, Santana do Livramento e Uruguaiana (espanhóis); Caxias do Sul (italianos); Noroeste Gaúcho (poloneses).

Ao longo de todo o período caracterizado pela imigração subvencionada, a origem dos imigrantes era principalmente do sul do continente europeu, sobretudo espanhóis e italianos, o que reafirma a importância da política de subvenção como fator de atração de imigrantes, associada a uma campanha deliberada que acenava com a possibilidade da propriedade da terra. Por outro lado, conclui Vignoli (2003), a forte expansão econômica do período também teve papel importante, porquanto revelava ao menos aos olhos dos imigrantes, a possibilidade de enriquecer e prosperar no Brasil, possibilidade quase impossível em seus países de origem.

\section{CONSIDERAÇÕES FINAIS}

Este artigo procurou identificar as principais contribuições e aportes teóricobibliográficos da História Econômica do Brasil em seus autores clássicos e contemporâneos, a fim de mostrar suas repercussões à luz da interpretação dos fluxos imigratórios entre o final do século XIX e início do século XX, a primeira era das grandes migrações em direção ao território brasileiro.

Verificou-se que tantos os autores clássicos da economia, como aqueles que circunscreveram sua análise enfatizando a temática específica das migrações após o primeiro período desenvolvimentista brasileiro, e que se identificam com o pensamento de vanguarda da geoeconomia, ponderam a importância da mão de obra imigrante na formação econômica do Brasil. Tal fato está intimamente vinculado às razões que originaram os fluxos migratórios, 
que combinaram necessidades internas de "braços" e ao mesmo tempo, fatores exógenos a esse processo, ou de "expulsão" de seus países de origem. O conhecimento anterior de processos de trabalho parece ter contribuído de forma decisiva para o desenvolvimento de alguns núcleos dinâmicos regionais.

Além de servirem para o povoamento e mão de obra barata em substituição aos processos de escravização e trabalho forçado, os imigrantes, em sua maioria alemães, italianos, espanhóis e japoneses apresentaram-se, contribuíram de forma decisiva à formação do capital laboral, humano e financeiro à primitiva indústria brasileira, onde o processo migratório adquiriu todas as condições para a mudança econômica-estrutural em que o Brasil passou durante o século XX.

Logo, identificamos que ainda no final do século XIX já com as subvenções às migrações encontravam-se as sementes para a posterior industrialização do país, bem como os anseios desenvolvimentistas, tanto no campo como na urbe, trazidos pelos próprios imigrantes, já que em seus países de origem era este o espírito à época, impulsionado e convulsionado pela ascensão selvagem do capitalismo inglês e alemão, especialmente.

Em suma, observou-se ainda que a literatura econômica clássica e contemporânea brasileira de História Econômica e Formação Econômica possuem basilares e importantes contribuições factuais, teóricas e, porque não, metodológicas, à análise dos fluxos imigratórios, fazendo com que as bases teóricas de autores, em especial, Furtado, Prado Júnior e Mello estejam vivos e contemporâneos aos fluxos imigratórios que voltam a se intensificar agora no primeiro quartel do século XXI.

Novamente a História Econômica traz aportes do passado, da Geoeconomia e da própria formação econômica do Brasil para a interpretação de fenômenos que se repetem e intensificam ao longo dos séculos, influindo diretamente na Economia, no caso, as migrações econômicas internacionais.

\section{REFERÊNCIAS BIBLIOGRÁFICAS}

BRASIL. Lei $n$. 601, de 18 de setembro de 1850. Dispõe sobre as terras devolutas do Império. Rio de Janeiro: Secretaria de Estado dos Negócios do Império, 1850. Disponível em: $<$ http://www.planalto.gov.br/ccivil_03/Leis/LIM/LIM601.htm>. Acesso em: 21 set. 2017. FURTADO, Celso Monteiro. Formação econômica do Brasil. 30. ed. São Paulo: Editora Nacional, 2001.

MARTINS, José de Souza. A Imigração e a crise do Brasil agrário. São Paulo: Pioneira, 1973. 
. A imigração espanhola para o Brasil e a formação da força-de-trabalho na economia cafeeira: 1880-1930. Revista História. São Paulo, n. 121, p. 5-26, 1989.

MELLO, João Manuel Cardoso de. O Capitalismo tardio. 3. ed. São Paulo: Brasiliense, 1984.

PRADO JUNIOR, Caio. História econômica do Brasil. 41. ed. São Paulo: Brasiliense, 1994.

UEBEL, Roberto Rodolfo Georg. As Influências da Espanha e Holanda na formação econômica do Brasil. Cadernos Camilliani. Cachoeiro do Itapemirim, v. 12, n. 1, p. 11-22, 2011.

. Impactos da Imigração Espanhola no Desenvolvimento Econômico e Territorial do Estado do Rio Grande do Sul no Século XX. Santa Maria, UFSM, 2012 (Trabalho de Conclusão de Curso em Ciências Econômicas da UFSM). Disponível em:

$<$ https://www.academia.edu/6310684/Impactos_da_Imigração_Espanhola_no_Desenvolvime nto_Econômico_e_Territorial_do_Estado_do_Rio_Grande_do_Sul_no_Século_XX $>$. Acesso em: 21 set. 2017.

VIGNOLI, Francisco. A Imigração e a formação do mercado de trabalho. In: REGO, José Márcio; MARQUES, Rosa Maria. Formação Econômica do Brasil. São Paulo: Saraiva, p. 112-134, 2003. 